\title{
A utilização do jogo enquanto estratégia de ensino dos Instrumentos de Política Urbana
}

The use of the game as a teaching strategy of the Urban Policy Instruments

La utilización del juego como estrategia de enseñanza de los instrumentos de política urbana

\section{Carolina Guida Cardoso do Carmo}

Mestre em Arquitetura, Tecnologia e Cidade - FEC/UNICAMP, Brasil Docente do Centro Universitário Padre Anchieta carolinagcdocarmo@gmail.com 


\section{INTRODUÇÃo}

O ensino, em qualquer área do conhecimento, deve ser frequentemente atualizado, desde seu conteúdo até as metodologias aplicadas em sala de aula, buscando se adaptar as demandas trazidas pelos novos estudantes. A partir dessa afirmativa, abrimos o trabalho com um questionamento considerado relevante: Quais os tipos de propostas metodológicas podem ser aplicados em sala de aula, para reforçar o conhecimento e dinamizar o ensino, também no ensino de arquitetura e urbanismo?

Moura e Cavalli (2013) colocam que é, portanto, necessário instigar e despertar o interesse dos alunos, motivando-os em se envolver nas discussões e atividades propostas, sendo necessário, assim, pensar em novas estratégias para garantir que a participação dos discentes se torne efetiva. Para Quirino, Campos e Oshima (2017), não podemos nos prender nas estratégias tradicionais de ensino, visto que os alunos vivem em uma nova geração e ritmo diário, fazendo com que as estratégias pedagógicas dos docentes devam se adequar a tais necessidades e tais dinâmicas fluídas. Os autores sugerem, assim, a utilização de jogos como um recurso pedagógico na construção do conhecimento.

\footnotetext{
Através do lúdico, o professor tem a chance de tornar sua prática pedagógica inovadora, pois além de desenvolver atividades divertidas, o professor pode proporcionar situações de interação entre os alunos, melhorando a forma de relacionamentos entre os mesmos. (KIYA, 2014, p. 10)
}

Existem diversas pesquisas que comprovam a utilização dos jogos com fins pedagógicas, principalmente na área da educação infantil, sendo possível citar exemplos como Coria-Sabini (2004), Lira (2009), Macedo (1995), Rodrigues (2013). Para esses autores, em suas respectivas pesquisas e recortes geográficos, não há dúvida do potencial didático do uso das atividades lúdicas como os jogos. Moura e Cavalli (2013) somam a isso que, mesmo sendo possível observar essa estratégia muita utilizado no ensino infantil, o jogo como atividade lúdica pode ser muito bem explorado no ensino superior, como em disciplinas do Curso de Arquitetura e Urbanismo. "O jogo, para ser utilizado como recurso pedagógico, precisa ser contextualizado significativamente para o aluno por meio da utilização de materiais concretos e da atenção à sua historicidade." (RAU, 2007, p.49)

Dessa forma, cabe aos professores identificar as demandas educacionais de seus alunos, assim como entender a necessidade de se utilizar de outras ferramentas de ensino para adaptar o ensino dos conteúdos - considerando suas complexidades, buscando minimizar tais dificuldades de compreensão e assimilação, assim como aproximar o conteúdo teórico da realidade vivenciada pelo corpo discente. 


\section{OBJETIVO}

De acordo com Quirino, Campos e Oshima (2017), aprender é uma necessidade constante dos alunos nas suas práticas acadêmicas e cotidiana. Dessa forma, fazer com que esses conteúdos tenham uma proximidade cada vez maior com a realidade, assim como tornar os mesmos mais perceptíveis das vivências dos alunos, pode tornar o aprendizado em um processo mais prazerosos e interessante. A partir desse trabalho, buscamos entender como a utilização de jogos em sala de aula, no ensino dos Instrumentos de Política Urbana, temática essa muito abordada em sala de aula de forma teórica e conceitual, pode aproximar os discentes de situações possíveis de serem vividas na realidade e, portanto, como influenciam no aprendizado e na compreensão de conteúdo didático.

\section{METODOLOGIA}

A experiência e os resultados apresentados são desenvolvidos a partir da utilização do Jogo do Estatuto da Cidade, em disciplina ofertada no segundo semestre de 2018 no curso de bacharelado em Arquitetura e Urbanismo do Centro Universitário Padre Anchieta, em JundiaíSP.

O jogo do Estatuto da Cidade é um material pertencente ao Kit das Cidades, criado pela Pontifício Universidade Católica de Campinas (PUCCAMP), em Parceria com o Instituto Polis (Instituto de Estudos, Formação e Assessoria em Políticas Sociais). O mesmo foi financiando no âmbito do Programa de Políticas Públicas da Fundação de Amparo à Pesquisa de São Paulo $(\text { FAPESP })^{1}$, buscando estabelecer uma ferramenta de capacitação para pessoas que lidassem com legislação urbanística, como técnicos de prefeituras, membros de movimentos de moradia, mercado imobiliário, entre outros, visto que com a vigência do Estatuto da Cidade (lei 10.257/2001) e as exigências previstas no mesmo, houve uma necessidade massiva de estabelecer treinamentos e capacitações, internas e externas aos órgãos gestores dos municípios, buscando aproximar tais mudanças à realidade das ações desses agentes.

O Jogo do Estatuto da Cidade, um dos componentes do Kit das Cidades, é estabelecido nos moldes dos jogos $\mathrm{RPG}^{2}$ e é uma simulação de uma mesa de negociação, envolvendo diversos personagens em um determinado local. Esse local pode ser definido a partir de três cenários distintos (exemplificados pelas figuras 1, 2 e 3), estabelecidos no jogo: uma cidade litorânea, uma cidade com características rurais e uma cidade de médio/grande porte. Para atuar nessas

\footnotetext{
${ }^{1}$ Programa de capacitação de agentes públicos e sociais para a formulação de políticas locais de regulação urbanística - no 98/14180-9. Modalidade Programa de Políticas Públicas; Instituição Parceira Instituto Pólis. Coordenadora Raquel Rolnik - PUCCAMP.

${ }^{2}$ Abreviação de Role Play Gaming, traduzido livremente para Jogo com Interpretação de Papéis.
} 


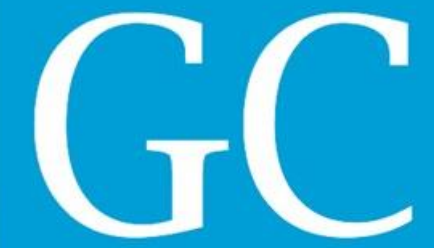

Revista Nacional de

cidades, cada participante assume um personagem existente no jogo e os mesmos devem usas os instrumentos urbanísticos previstos no Estatuto das Cidades para negociar e resolver as questões colocadas como prioritárias no decorrer do jogo.

A partir da utilização do jogo em sala de aula, com duração média de 1 hora, foi solicitado para os alunos que fosse redigido um relatório, em grupo, em que fossem ressaltados os seguintes aspectos de suas percepções a partir da experiência: 1) a relevância do jogo para a fixação de conceitos e para análise crítica individual; 2) como as tomadas de decisões individuais influenciaram no resultado do jogo e 3) quais foram as (diversas) soluções observadas para o problema proposto para cada grupo.

Figuras 1, 2 e 3: Parte do tabuleiro do Jogo Estatuto da Cidade, em seus possíveis cenários

Fonte: http://polis.org.br/publicacoes/

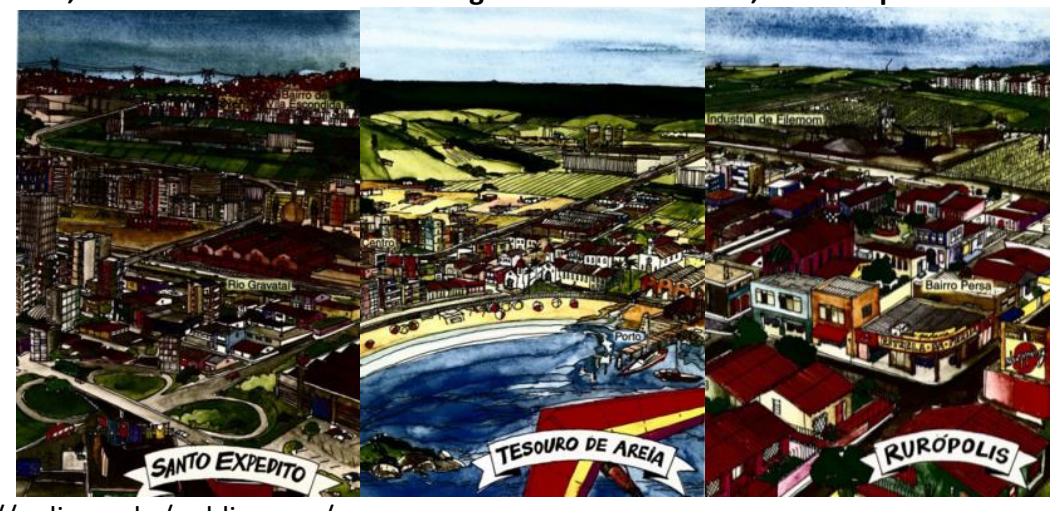

\section{RESULTADOS}

Para o jogo em sala de aula, foram divididos dois grupos, sendo que cada um deles trabalhou com uma questão norteadora referente à cidade de Santo Expedito, uma das cidades-cenários do jogo, representando uma cidade de grande porte. O grupo 1 desenvolveu sua discussão a partir da seguinte situação:

\footnotetext{
Um shopping quer se instalar no bairro do Félix, área nobre da cidade de Santo Expedito. O shopping será de alto padrão e destinado principalmente para as classes mais abastadas da cidade. A comunidade local é muito articulada, pois possui representantes nos diversos setores da administração da cidade e também no Ministério Público. [...] Questão orientadora: Os participantes deverão discutir os instrumentos que possibilitem à comunidade propor mudanças no projeto, bem como relacionar as possíveis alternativas para os problemas apresentados.
}

O grupo 2, por sua vez, desenvolveu sua discussão a partir de tal problemática: 


\begin{abstract}
[...] Diversas associações de moradores e movimentos por moradia estão reivindicando junto à Prefeitura Municipal alternativas para a questão de infra-estrutura nos bairros, ou outros espaços para a construção de moradias. No centro da cidade há grandes áreas desocupadas. A Secretaria Municipal de Planejamento e os movimentos populares estão promovendo um seminário sobre gestão urbana e convidaram os diversos setores da sociedade. [...] Questão orientadora: Ao final do Seminário os participantes do debate deverão redigir um documento contendo uma proposta que atenda as reivindicações dos movimentos.
\end{abstract}

Durante a experiência do jogo, foi perceptível, em um início dos debates, um certo distanciamento e hesitação por parte dos alunos de interpretar seus personagens e "lutar" por seus interesses, sejam eles coletivos ou individuais. Entretanto, no decorrer do jogo, nos momentos em que apareciam sugestões de determinados personagens e que não necessariamente atendiam um anseio coletivo, os alunos começaram a ser articular, ora com seu personagem e suas características, ora entre si, para poderem argumentar e vencer certas sugestões que eram compreendidas como pesarosas para o grupo.

Também foi percebido, durante a experiência (e ressaltado por um grupo, em seu relatório) de que muitas vezes, era difícil o grupo manter o fodo da discussão e dar o andamento considerado apropriado, até mesmo pelos alunos, para chegarem em uma solução coletiva. Esse entrave, mesmo não sendo observado pelos alunos como uma característica similar aos debates públicos reais, é uma colocação que demonstra uma percepção inicial de como é desafiador estabelecer esses pontos de debates com agentes que tem interesses distintos entre si.

A partir do relato dos alunos, independentemente do grupo que tenha participado para a experiência, foi observado que o jogo teve extrema importância para aproximar uma aula, muitas vezes limitada à lógica da discussão teórico-conceitual, de uma experiência mais realista da aplicabilidade desse conteúdo. O jogo, ainda de acordo com os alunos, foi responsável por transferir o estudo dos instrumentos de política urbana do campo teórico para um campo experimental da realidade urbana, onde foi possível: 1) entender a aplicabilidade desses instrumentos de uma forma mais próxima à realidade vivida em uma dinâmica de debates reais para gestão do espaço urbano; 2) auxiliar no entendimento de cada um dos instrumentos e suas especificidades de aplicação, assim como a possibilidade de solucionar um problema específico a partir da utilização e/ou sobreposição de diversos instrumentos; 3 ) observar a relevância da participação dos cidadãos nos debates e na gestão do espaço urbano, visto que, a opinião de personagens, muitas vezes considerados irrelevantes, no imaginário coletivo e social, para um debate sobre cidade e formas de geri-la, foi de extrema importância para a tomada de decisão em prol do coletivo.

Também foi muito ressaltado, dentro dos materiais elaborados pelos grupos que, mesmo que as soluções propostas tenham sido elaboradas de forma coletiva, buscando atender uma parte majoritária dos personagens e suas demandas, não foi possível sanar todas as expectativas quanto aos resultados possíveis que, muitas vezes, iriam privilegiar poucos em detrimento de 
muitos moradores - percepção essa amplamente vinculada com a realidade da política urbana. "Percebemos que nas decisões, nem todos saíram satisfeitos, porém isso acontece, já que o que deve ser levado em consideração é o bem comum e coletivo e não o interesse particular de poucos" (Relato de Grupo).

\section{CONCLUSÃO}

A partir da análise desse trabalho, observamos a potencialidade, não só na concepção docente como também na concepção dos alunos, dessa ferramenta lúdica no ensino de conteúdos ligados à cidade, como é o caso dos Instrumentos de Política Urbana, buscando trazer uma aproximação da temática com sua real utilização.

Entendemos que, não é possível trazer conclusões delineadas a partir de uma experiência isolada, entretanto, consideramos que é podemos ressaltar pontos observados como de extrema importância para uma reflexão acerca dessa estratégia.

Essas ferramentas que podem ser utilizadas como ferramentas de ensino, como é o caso do Jogo do Estatuto da Cidade, que proporciona grande motivação e participação por parte dos alunos, possibilita muitos caminhos que, para Sansão e Pessoa (2013), podem contribuir para um ensino mais atualizado, mais dinâmico e que, não necessariamente, perde em seriedade e consistência.

Também ressaltamos que, sendo esses alunos parte dos futuros profissionais que poderão trabalhar com a gestão da cidade e, consequentemente, com a formulação das políticas e instrumentos de regulação urbana, estimulá-los desde o período universitário a experimentar essa realidade, mesmo que em uma situação hipotética, pode ser um caminho para aproximálos de uma vivência estudantil e/ou profissional que, de acordo com Chee (2007), valoriza o processo de incorporação do conhecimento e não só o acúmulo de informação.

Esperamos, por fim, que tais estímulos estabelecidos dentro de sala de aula transponham os limites dos centros de ensino e os levem aos debates reais da cidade, para não só vivenciar as disputas interpretadas em aula, como para que se percebam enquanto agentes de transformação do espaço urbano.

\section{REFERÊNCIAS BIBLIOGRÁFICAS}

CHEE, Y. S. Embodiment, embeddedness, and experience: Game-based learning and the construction of identity. Research and Practice in Technology Enhanced Learning, 2(01), 3-30. 2007.

CORIA-SABINI, M. A. Jogos e brincadeiras na educação infantil. Campinas: Papirus. 2004.

KIYA, Marcia Cristina da Silveira. O uso de Jogos e de atividades lúdicas como recurso pedagógico facilitador da aprendizagem. UNIVERSIDADE ESTADUAL DE PONTA GROSSA. Programa de Desenvolvimento Educacional. Ortigueira. 2014 


\section{Revista Nacional de}

Gerenciamento de Cidades

National Journal of Cities Management

LIRA, A. C. M. Problematizando o uso dos jogos e das brincadeiras na educação das crianças de $\mathbf{0}$ a 6 anos: uma análise de propostas exemplares. Tese (Doutorado-Programa de Pós-Graduação em Educação) - Universidade de São Paulo, São Paulo, 2009.

MACEDO, Lino de. Os jogos e sua importância na escola. Cad. Pesqui., São Paulo, n. 93, maio 1995.

MOURA, Patrícia; CAVALLINI, Silvana. Jogo de percepção urbana: uma proposta pedagógica no ensino superior Ciência em Movimento | Ano XV | № 31 | 2013.

QUIRINO, Thalyta M. F; CAMPOS, Carmen,C. V.; OSHIMA, Rosemary M. S. Uso de Jogos no Ensino Superior Como Estratégia Pedagógica. Revista Tecnologias na Educação - Ano 9 - Número/Vol.22 - Edição Temática VI-II Simpósio Nacional de Tecnologias Digitais na Educação (II-SNTDE). UFMA, 2017.

RAU, M. C. T. D. A ludicidade na educação: uma atitude pedagógica. Curitiba: Ibpex, 2007.

RODRIGUES, Lídia da Silva. Jogos e brincadeiras como ferramentas no processo de aprendizagem lúdica na alfabetização. Dissertação (mestrado) - Universidade de Brasília, Faculdade de Educação, Programa de PósGraduação, 2013.

SANSÃO, Adriana; PESSOA, Alexandre. Outra forma de aprender: o ensino de arquitetura como um jogo. Arquitextos, São Paulo, ano 13, n. 152.03, Vitruvius, jan. 2013 